\title{
Environmental Exposure to Lead, Vanadium, Copper and Selenium: Possible Implications in the Development of Autism Spectrum Disorders
}

\author{
A. O. Akinade1, I. O. Omotosho ${ }^{*}{ }^{\circledR}$, I. A. Lagunju' ${ }^{2}$ M. A. Yakubu ${ }^{3}$ \\ ${ }^{1}$ Department of Chemical Pathology, College of Medicine, University of Ibadan, Ibadan, Nigeria \\ ${ }^{2}$ Department of Paediatrics, College of Medicine, University of Ibadan, Ibadan, Nigeria \\ ${ }^{3}$ Department of Environmental Science and Technology, Texas Southern University, Houston, TX, USA \\ Email: *iomotosho2014@gmail.com
}

How to cite this paper: Akinade, A.O., Omotosho, I.O., Lagunju, I.A. and Yakubu, M.A. (2019) Environmental Exposure to Lead, Vanadium, Copper and Selenium: Possible Implications in the Development of Autism Spectrum Disorders. Neuroscience \& Medicine, 10, 247-258.

https://doi.org/10.4236/nm.2019.103019

Received: July 8, 2019

Accepted: September 23, 2019

Published: September 23, 2019

Copyright $\odot 2019$ by author(s) and Scientific Research Publishing Inc. This work is licensed under the Creative Commons Attribution International License (CC BY 4.0).

http://creativecommons.org/licenses/by/4.0/

\begin{abstract}
Human exposure to toxic metals is on the increase especially in the developing world; this is compounded by the almost unavoidable application of the metals domestically and industrially and their implication in several genetic defects, aging and some chronic illnesses including Autism Spectrum Disorders (ASD). This study investigated the concentration of toxic metals $(\mathrm{Pb}$ and $\mathrm{V}$ ) and micro-essential elements ( $\mathrm{Cu}$ and $\mathrm{Se}$ ) in children with ASD and controls in Nigeria towards establishing their possible associations with the aetiopathogenesis of ASD. Eight children clinically diagnosed by Paediatric Neurologist and Child Psychiatrist for ASD using DMS-IV and fifteen apparently healthy children (age range $2-12$ years) were recruited as cases and controls respectively. Plasma levels of $\mathrm{Pb}, \mathrm{V}, \mathrm{Cu}$ and Se were analyzed using Induction ICP-MS. Results were analyzed using students t-test. The mean plasma lead and vanadium levels were $(7.92 \pm 1.30 \mu \mathrm{g} / \mathrm{dl} ; 1.07 \pm 0.22 \mu \mathrm{g} / \mathrm{dl})$ and $(6.83 \pm 0.72 \mu \mathrm{g} / \mathrm{dl} ; 2.59 \pm 0.48 \mu \mathrm{g} / \mathrm{dl})$ in children with ASD and in controls respectively. The result showed that blood lead level in ASD was slightly increased but not significant when compared with control $(\mathrm{p}<0.433)$. On the other hand, plasma vanadium concentration in ASD was significantly reduced $(1.07 \pm 0.22 \mu \mathrm{g} / \mathrm{dl})$ when compared with control $(2.59 \pm 0.48 \mu \mathrm{g} / \mathrm{dl})(\mathrm{P}$ $<0.038)$. Mean plasma copper was similar in all participants $(1.98 \pm 0.13,2.23$ $\pm 0.12)$ but selenium concentrations were significantly reduced $(0.37 \pm 0.05$ $\mathrm{mg} / \mathrm{L} ; 0.57 \pm 0.02 \mathrm{mg} / \mathrm{L}$ ) in ASD relative to controls respectively. Given the physiological functions of vanadium and selenium, the observed reduced levels of the two elements in children with ASD may account for the speech
\end{abstract}


and other neurological dysfunctions of the brain in ASD.

\section{Keywords}

Toxic and Essential Metals, Autism Spectrum Disorder, Children, Aetiopathogenesis

\section{Introduction}

Autism Spectrum Disorders (ASD) are a heterogeneous group of neurodevelopmental disorders that are behaviourally defined and characterized by impairments in communication and social interaction along with restrictive and repetitive behaviours beginning in infancy and toddler years [1] [2]. Several reasons have been proffered as the pathophysiology of ASD, however, contribution of industrial chemicals and metallic pollutants widely disseminated in the environment have been suggested as important contributors to the development of this condition [3] [4]. The vulnerability of the developing human brain in-utero has also lent credence to its prevalence among children. Recently, interaction between genes and the toxicants has been suggested as basis of genetic modulation and the development of ASD [5]. Thus, due to this complex pathophysiology of ASD, many authors are of the opinion that both genetic and environmental factors (and their interactions) are strongly linked in the development of the disorders [6]. The possibility of this assertion has been heightened by the recent increase in prevalence of the disorder worldwide.

Specifically, in recent times, research and clinical studies have implicated physiological and metabolic systems that transcend specific organ dysfunction, such as immune dysregulation, inflammation, impaired detoxification, impaired redox regulation/oxidative stress and energy generation/mitochondrial systems [7] [8]. These imply that ASD may arise from, or at least involve, systemic physiological abnormalities rather than being a purely central nervous system disorder in a subset of individuals with ASD [9]. It is in this respect that the involvement of trace and toxic metals (which in a developing economy like ours are inevitable pollutants) and their interaction with gene development especially in subjects that are actively or passively exposed to them become important.

Trace elements are chemical micronutrients which are required in small amounts but play a vital role in various physiological and metabolic processes occurring within living tissues [10] [11]. There are threshold levels for most of these trace elements; hence, their deficiency or excessive accumulation may cause serious changes in the body leading to disruption of important enzyme activities [12]. The immature blood-brain barrier, neuronal growth migration and myelination processes that occur on a specific and rapid schedule in a developing foetus may largely facilitate development of ASD in children.

In pregnancy, excessive exposure to heavy metals and some trace elements has 
been shown to be harmful to the developing fetus and may be harmful to the human nervous system, even at low levels [13] [14]. Also, several studies have reported that trace metals could easily cross the placenta and affect cognitive development [15] despite its function as a barrier protecting the fetus from toxic metal exposure. The possible interaction between these toxic metals either in modulating the nutritional function of the essential metals or on genetic pairing remains issues in the aetiopathogenesis of ASD. Until recently, the study of potential environmental toxicant contributions to the development of ASD has been generally "neglected" [16], hence the need for a clearer look at their contribution to the development of ASD especially with the gradual increase in the prevalence of this disorder.

\section{Subjects and Methods}

Recruitment: A total number of 23 participants were recruited by convenience sampling method for this pilot study between August and November 2015. This comprised of eight (8) children clinically diagnosed for ASD with mean age 5.25 years \pm 0.37 and fifteen (15) apparently healthy children with mean age 7.87 years \pm 0.89 as controls. All children recruited for this study received routine childhood vaccinations.

Selection: Paediatric Neurologist and Child Psychiatrist clinically selected the subjects after proper evaluations and diagnosis according to Diagnostic and Statistical Manual of Mental Disorder DMS-IV-DR; DMS-5 classification. Children and their parent's history were taken.

Ethical approval was obtained from the UCH/UI joint Ethical Committee.

Informed consent was obtained from each subject through their parents.

Inclusion criteria: Clinically diagnosed children with ASD that their parents gave informed consent were recruited for the study.

Exclusion criteria: Participants that were suffering from liver or kidney disease, anemia, or current treatment for iron deficiency, progressive neurological disorders, or epilepsy were excluded from the study.

Method: History of all children in the study was taken covering: parent socio-economic status, pregnancy history, developmental milestones, dietary history, and environmental exposure factor. History of major childhood illnesses and immunizations were taken and clinical examination of all body systems with special emphasis on neurological examination was performed by a Neuro-paediatrician. All autistic children were subjected to a full clinical child psychiatric evaluation for diagnosis of autistic spectrum disorder and exclusion of other psychiatric disorders according to Diagnostic and Statistical Manual of Mental Disorders based on DSM-IV-TR; DSM-5 [17] [18].

Blood collection: About $2 \mathrm{mls}$ of venous blood was collected from each participant from the ante-cubital vein. Blood was carefully dispensed into lithium heparin bottles to avoid haemolysis. Blood samples were centrifuged at 3000 r.p.m. at room temperature for 10 minutes using Centeur 2-centrifuge (Fiston 
centrifuge, manufactured in England) to obtain plasma which was promptly separated into another clean plane bottle. All samples were kept frozen at $-20^{\circ} \mathrm{C}$ until they were ready for analysis. They were analyzed for $\mathrm{Cu}, \mathrm{Se}, \mathrm{V}$ and $\mathrm{Pb}$ using Induction Coupled Plasma-Mass Spectrometry (ICP-MS).

Statistical analysis: Appropriate in-built software in the instrument was used to calculate the result of the analysis with inclusion of standards and controls. The results were converted to SI units from part per billion (ppb) using appropriate conversion factors.

Data were reviewed, coded, tabulated and analyzed using statistical package for social science (SPSS 20.0)

Mean standard error $(\mathrm{MEAN} \pm \mathrm{S}$.E) was used to express descriptive statistics of the results while student t-test was used to access the statistical significance of the difference between the two groups. $\mathrm{P}$ value of 0.05 was regarded significant.

\section{Results}

Table 1 showed gender percentage distribution; 6 boys (75\%) and 2 girls (25\%) constituted the ASD group while 8 boys (53.3\%) and 7 girls (46.7\%) constituted the neurotypical (control) group. The result showed that $6(75.0 \%)$ of the ASD group were 1st born among the siblings. It was revealed from the results that the parents of the two groups belong to the same socio-economic status.

Table 1. Comparison of \% gender distribution and socio-economic grouping of the two groups.

\begin{tabular}{|c|c|c|c|c|c|}
\hline Variables & Response & $\operatorname{ASD}(\mathrm{N}=8)$ & $\mathrm{NC}(\mathrm{N}=15)$ & $\mathrm{X}^{2}$ & p-Value \\
\hline \multirow{2}{*}{ Sex } & Male & $6(75 \%)$ & $8(53.3 \%)$ & \multirow{2}{*}{1.028} & \multirow{2}{*}{0.311} \\
\hline & Female & $2(25 \%)$ & $7(46.7 \%)$ & & \\
\hline \multirow{6}{*}{ Child birth order } & $1 \mathrm{ST}$ & $6(75.0 \%)$ & $8(53.3 \%)$ & \multirow{6}{*}{2.008} & \multirow{6}{*}{0.366} \\
\hline & $2 \mathrm{ND}$ & $2(25.0 \%)$ & $2(13.3 \%)$ & & \\
\hline & $2 \mathrm{RD}$ & $0(0.0 \%)$ & $2(13.2 \%)$ & & \\
\hline & $3 \mathrm{RD}$ & $0(0.0 \%)$ & $3(20.0 \%)$ & & \\
\hline & $4 \mathrm{TH}$ & $0(0.0 \%)$ & $0(0.0 \%)$ & & \\
\hline & $5 \mathrm{TH}$ & $0(0.0 \%)$ & $0(0.0 \%)$ & & \\
\hline \multirow{4}{*}{$\begin{array}{l}\text { Mother's level } \\
\text { of education }\end{array}$} & $\mathrm{PE}$ & $0(0.0 \%)$ & $0 .(0.0 \%)$ & \multirow{4}{*}{1.840} & \multirow{4}{*}{0.399} \\
\hline & PPE & $1(12.5 \%)$ & $4(26.7 \%)$ & & \\
\hline & PSE & $5(62.5 \%)$ & $5(33.3 \%)$ & & \\
\hline & PGE & $2(25.0 \%)$ & $6(40.0 \%)$ & & \\
\hline \multirow{4}{*}{$\begin{array}{l}\text { Father's level } \\
\text { of education }\end{array}$} & $\mathrm{PE}$ & $0(0.0 \%)$ & $0(0.0 \%)$ & \multirow{4}{*}{4.214} & \multirow{4}{*}{0.122} \\
\hline & PPE & $1(12.5 \%)$ & $3(20.0 \%)$ & & \\
\hline & PSE & $5(62.5 \%)$ & $3(20.0 \%)$ & & \\
\hline & PGE & $2(25.0 \%)$ & $9(60.0 \%)$ & & \\
\hline
\end{tabular}

Legend: PE-Primary Education, PPE—Post Primary Education, PSE—Post Secondary Education, PGE-Post Graduate Education. 
Table 2. Comparison of biodata variables in ASD and control (mean \pm S.E.).

\begin{tabular}{ccccc}
\hline Variables & ASD $(\mathrm{N}=8)$ & Control $(\mathrm{N}=15)$ & t-Value & p-Value \\
\hline Child's age $(\mathrm{yrs})$ & $5.25 \pm 0.37$ & $7.87 \pm 0.89$ & -2.723 & 0.050 \\
Mother's age at birth $(\mathrm{yrs})$ & $28.63 \pm 1.59$ & $30.24 \pm 1.29$ & -1.028 & 0.316 \\
Father's age at birth (yrs) & $32.88 \pm 1.60$ & $34.40 \pm 1.097$ & -0.990 & 0.333 \\
Child's weight $(\mathrm{kg})$ & $19.31 \pm 0.61$ & $19.67 \pm 2.22$ & 0.240 & 0.814 \\
Child's birth weight $(\mathrm{kg})$ & $3.38 \pm 0.07$ & $2.86 \pm 0.23$ & 1.629 & 0.118 \\
\hline
\end{tabular}

*significant at $\mathrm{p}<0.05$.

Table 3. Comparison of trace and toxic elements levels in ASD and control (mean \pm S.E.).

\begin{tabular}{ccccc}
\hline Variables & ASD $(\mathrm{N}=8)$ & Control $(\mathrm{N}=15)$ & t-Value & p-Value \\
\hline Copper $(\mathrm{mg} / \mathrm{L})$ & $1.98 \pm 0.13$ & $2.23 \pm 0.12$ & -1.290 & 0.211 \\
Selenium $(\mathrm{mg} / \mathrm{L})$ & $0.37 \pm 0.05$ & $0.57 \pm 0.02$ & -5.316 & $0.000^{*}$ \\
Lead $(\mu \mathrm{g} / \mathrm{dl})$ & $7.92 \pm 1.30$ & $6.83 \pm 0.72$ & 0.799 & 0.433 \\
Vanadium $(\mu \mathrm{g} / \mathrm{dl})$ & $1.07 \pm 0.22$ & $2.59 \pm 0.48$ & -2.219 & $0.038^{*}$ \\
\hline
\end{tabular}

*significant at $\mathrm{p}<0.05$.

Table 2 showed the biodata of participants. There were no significant differences in the children's age, mother's age at birth, father's age at birth, children's birth weight and children weight between ASD and control. It may be said that there were no disparities in recorded biodata of the two groups.

Table 3 showed the comparison of levels of $\mathrm{Pb}, \mathrm{V}, \mathrm{Cu}$ and $\mathrm{Se}$ in ASD and control groups. The result showed there were no significant differences in the mean levels of $\mathrm{Cu}(1.98 \pm 0.13 \mathrm{mg} / \mathrm{L} ; 2.23 \pm 0.12)$ and $\mathrm{Pb}(7.92 \pm 1.30 \mu \mathrm{g} / \mathrm{dl} ; 6.83$ $\pm 0.72 \mu \mathrm{g} / \mathrm{dl})$ in ASD and controls respectively $(\mathrm{p}<0.211 ; \mathrm{p}<0.433)$. However, Se level was significantly reduced in ASD when compared with the control (0.37 $\pm 0.05 \mathrm{mg} / \mathrm{L}$ and $0.57 \pm 0.02 \mathrm{mg} / \mathrm{L}$ ) respectively ( $\mathrm{p}<0.000$ ). Also, plasma vanadium level was significantly reduced in ASD compared to controls $(1.07 \pm 0.22$ $\mu \mathrm{g} / \mathrm{dl}$ and $2.59 \pm 0.48 \mu \mathrm{g} / \mathrm{dl})$ respectively $(\mathrm{p}<0.038)$.

\section{Discussion}

Autism spectrum disorders (ASDs) are a heterogeneous group of neurodevelopmental disabilities that can cause significant social, communication and behavioral challenges that are characterized by impairments in communication and social behaviors beginning in infancy and toddler years [1]. It has a prevalence of $1.47 \%$ in Americans [19] and 2.3\% in Nigerian children [20]. ASD has been reported to account for 7.7 million disability adjusted life years in 2010 and was the leading mental cause of disability in children under five in terms of years lived with disability [21]. While the exact etiology of ASD remains unknown, novel technologies and large population-based studies have provided new insight into the risk characteristics of ASD and the possible role of environmental factors in its etiology [22] [23]. 
The study was designed to determine the plasma levels of $\mathrm{V}, \mathrm{Cu}$, Se and $\mathrm{Pb}$ in ASD and based on their biochemical roles, to compare with controls in order to assess their possible contribution to the disorder. The increased blood $\mathrm{Pb}$ level (though not significant) found in this study may be pathognomonic of the disease. This may be the basis of the impaired cognitive and behavioural deficits characteristic of this condition. This may be facilitated by the increased sensitivity of the brain to lead exposure [24]. Lead has been severally reported to displace other elements like calcium and magnesium from most of their reactive sites through several processes. The pathological effect especially when present in a prolonged and excessive amount may contribute to the development of ASD. Its effect inducing cognitive and behavioral deficits in children and adult resulting in a distinct neurological effect, with different brain targets and modes of action has been severally documented [25] [26]. Hence, the possible deleterious effect of air-borne lead in children compared to adults because of the higher respiratory and metabolic activities of the former may have also facilitated the development of ASD in these children. Previous studies done on hair lead level reported increased lead levels in ASD compared to controls [27] [28] [29] just as it has been observed in this study that blood lead level in ASD was higher than in controls. This was also in agreement with other studies that reported increased blood levels in ASD [30] [31]. Secondly, since calcium has also been reported to be selectively displaced by lead when the latter is in excess; the increased lead level in this study may be precipitated by the hypocalcaemia observed in children with ASD which was reported earlier by this team [30]. Nutritionally, children with ASD have been reported to have low poor eating habits with attendant low nutritional compliments. It may therefore be possible that reduced essential elements level in ASD children may also exacerbate the development of autism especially in an environmentally prone setting.

The increased blood lead level observed in this study may also be implicated in a disturbance in the redox activity of the brain. This is because increased blood lead level has been reported to have a variety of effects on synaptic mechanisms and structures resulting in formation of reactive oxygen species, speeding mitochondrial self-destruction through formation of the permeability transition pore, and priming activation of programmed cell death processes [32] [33]. Lead has also been shown to interfere with neurotransmitter release, disrupting the function of GABAergic, dopaminergic, and cholinergic systems [32]. However, there have been other reports suggesting that there is an inherent higher susceptibility of certain children to lead toxicity relative to others. It may therefore be inferred that children with ASD may have problems with the chemical pathway that allows them to detoxify metals to alleviate different cluster of autistic symptoms. Although, this is equivocal, evidence shows that autistic children show an increased build-up of toxins which may not arise simply from excessive exposure but from a marked inability to process and eliminate toxins from the body. Such a mechanism could lead to accumulation of toxic heavy metals and chemical toxins with the attendant risk of the accumulation leading 
to increase in free radical activity in the body [34]. Studies on this element have been very scanty especially in humans.

The major source of exposure to vanadium for the general population is food. The major report on this element has been on its insulin-like action in-vivo. Vanadium in the form of vanadate and vanadyl sulfate has been shown to improve the effect of insulin in diabetic animals; artificially induced diabetes in rats can be reversed by vanadate [35]. Large doses also affect serum fat and cholesterol levels, though more research in this area is needed. Biochemically, the possibility that vanadium may play a role in the regulation of $\mathrm{Na}^{+} / \mathrm{K}^{+}$-exchanging ATPase, phosphoryl-transfer enzymes, adenylate cyclase and protein kinases has been reported. The possible role of the vanadyl ion as an enzyme cofactor and its roles in hormone, glucose, lipid, bone and tooth metabolism have also been discussed [36]. No specific biochemical function has yet been identified for vanadium in higher animals. However, the recent discovery of vanadium-activated enzymes in lower forms of life lends credence to the view that vanadium has similar roles in higher animals. In this study, plasma level of this essential element was found to be low in children with ASD. The level was significantly low in comparison to that of control children. Based on what has been reported in lower animals, the essentiality of this element for normal growth and development is not in doubt. Hence, the observed reduced level in children with ASD may be associated with underdevelopment of the cognitive functions of the brain in this group of neurodevelopmental disorder. Biochemically, this may be due to its role in $\mathrm{Na}^{+} / \mathrm{K}^{+}$ATPase and Phosphoryl enzyme transfer activities which are all linked to calcium homeostasis making growing children more vulnerable especially in sensitive organs like in their brain.

Copper is one of the micro elements included in this study. It was found that the $\mathrm{Cu}$ level in ASD was reduced (though not significantly) when compared to control. Copper is a trace element essential for body cellular functions. Characteristically, $\mathrm{Cu}$ could act as an oxidant or as an antioxidant depending on the concentration and the prevailing circumstance [37]. Functionally, copper promotes neurological activities and plays a role in antioxidant defense system of the body. $\mathrm{Cu}$ deficiency is known to affect the central nervous system. Specifically, information from animal studies suggests that $\mathrm{Cu}$ deficiency may be a strong factor in the pathogenesis of Parkinson's disease in humans especially since the level of one of the neurotransmitters (dopamine) was low in both $\mathrm{Cu}$ deficient animals and in patients with Parkinson's. Cudeficiency has also been implicated in Menke's disease which is a neurodevelopmental inherited disease [38]. $\mathrm{Cu}$ deficiency has also been shown to be exacerbated by the increased presence of elements like lead and cadmium. Hence, since $\mathrm{Cu}$ is largely derived from the diet, deficient nutritional status occasioned by reduced appetite in ASD may have also contributed to the progression of the pathological symptoms of ASD especially in a vulnerable environment. The observed reduced Cu level in ASD children in this study may have largely been accentuated by the above prevailing factors resulting in the progression of the pathological symptoms of the 
disorder [39]. Although findings in this study were contrary to previous studies that reported elevated copper levels in ASD compared with control [40] [41] [42], this work was in agreement with the report of Craciun et al. that reported reduced $\mathrm{Cu}$ level in children with ASD [43].

Selenium is an essential trace metal needed in the production of antioxidants enzymes. As Selenoproteins, they are essential for brain development, redox control, and preventing and reversing oxidative damage in the brain and neuroendocrine tissues [44]. This important redox property of Se may have been compromised by the reduced Se level observed in ASD children in this study. The reduced selenium level found in this study may have contributed to the pathophysiology of ASD especially since glutathione is a very prominent antioxidant in the neuroendocrine tissues of the brain. Glutathione is known to be a major redox buffer in the trans-sulfuration pathway in the neuroendocrine tissue [45], this process ensures replication of the redox form of the antioxidant which contributes to the transmission of impulse along the nerves. It may therefore be inferred that a reduced level of Se greatly hampers this mechanism and may largely account for some of the neuro-behavioural changes associated with ASD. Control of intracellular oxidative tone and findings of increased oxidative damage in children with ASD may be indicative of disruptions of selenoenzyme activities resulting from reduced selenium levels. This finding agreed with previous studies that reported reduced Se levels in analysis done on hair and red blood cells in their studies [46] [47] [48].

\section{Conclusion}

The hallmark of ASD in children in this environment may be indicated by a deficiency in the essential trace elements- $\mathrm{V}, \mathrm{Cu}$ and $\mathrm{Se}$ with a concurrent increase in $\mathrm{Pb}$ especially in environmentally vulnerable children. Abnormality in the levels of these elements may be good biomarkers of ASD especially in environmentally vulnerable children with or without the presence of the known clinical symptoms of ASD.

\section{Limitation}

The small sample size was a limitation in this study, a larger sample size may reveal more. Also, control of environmental pollution is difficult in this part of the world; this may be due to level of public health awareness.

\section{Conflicts of Interest}

The authors declare no conflicts of interest regarding the publication of this paper.

\section{References}

[1] WHO (2012) In World Health Organization, Geneva.

[2] National Institute of Mental Health (2011) What Is Autism Spectrum Disorder. 
[3] Grandjean, P. (2013) Only One Chance. How Environmental Pollution Impairs Brain Development and How to Protect the Brains of the Next Generation. Oxford University Press, New York. https://doi.org/10.1093/acprof:oso/9780199985388.001.0001

[4] Grandjean, P. and Perez, M. (2008) Development Neurotoxicity: Implications of Methylmercury Research. International Journal of Environment and Health, 2, 417-428. https://doi.org/10.1504/IJENVH.2008.020933

[5] Rice, D. and Barone, S.Jr. (2000) Critical Periods of Vulnerability for the Developing Nervous System: Evidence from Humans and Animal Models. Environmental Health Perspectives, 108, 511-533. https://doi.org/10.1289/ehp.00108s3511

[6] Blaurock-Busch, E., Amin, O.R. and Rabah, T. (2011) Heavy Metals and Trace Elements in Hair and Urine of a Sample of Arab Children with Autistic Spectrum Disorder. Maedica (Buchar), 6, 247-257.

[7] Blaurock-busch, E., Amin, O.R., Dessoki, H.H. and Rabah, T. (2012) Toxic Metals and Essential Elements in Hair and Severity of Symptoms among Children with Autism. Maedica: A Journal of Clinical Medicine, 7, 38-48. https://doi.org/10.1016/S0924-9338(12)74444-9

[8] Rossignol, D.A. and Frye, R.E. (2012) A Review of Research Trends in Physiological Abnormalities in Autism Spectrum Disorders: Immune Dysregulation, Inflammation, Oxidative Stress, Mitochondrial Dysfunction and Environmental Toxicant Exposures. Molecular Psychiatry, 17, 389-401. https://doi.org/10.1038/mp.2011.165

[9] Ming, X., Brimacombe, M., Chaaban, J., Zimmerman-Bier, B. and Wagner, G.C. (2008) Autism Spectrum Disorders: Concurrent Clinical Disorders. Journal of Child Neurology, 23, 6-13. https://doi.org/10.1177/0883073807307102

[10] Herbert, M.R. (2005) Autism: A Brain Disorder or a Disorder That Affects the Brain. Clinical Neuropsychiatry, 2, 354-379.

[11] Prashanth, L., Kattapagari, K.K., Chitturi, R.T., Baddam, V.R. and Prasad, L.K. (2015) A Review on Role of Essential Trace Elements in Health and Disease. Journal of Dr. NTR University of Health Sciences, 4, 75-85.

https://doi.org/10.4103/2277-8632.158577

[12] Bhattacharya, P.T., Misra, S.R. and Hussain, M. (2016) Nutritional Aspects of Essential Trace Elements in Oral Health and Disease: An Extensive Review. Scientifica, 2016, Article ID: 5464373. https://doi.org/10.1155/2016/5464373

[13] Skalny, A.V. (2014) Bioelements and Bioelementology in Pharmacology and Nutrition: Fundamental and Practical Aspects. In: Atroshi, F., Ed., Pharmacology and Nutritional Intervention in the Treatment of Disease, InTech, Rijeka, 225-241. https://doi.org/10.5772/57368

[14] Rahbar, M.H., Samms-Vaughan, M., Dickerson, A.S., Loveland, K.A., Ardjomand-Hessabi, M., Bressler, J., Shakespeare-Pellington, S., Grove, M.L. and Boerwinkle, E. (2015) Factors Associated with Blood Lead Concentrations of Children in Jamaica. Journal of Environmental Science and Health, Part A, 50, 529-539.

[15] National Scientific Council on the Developing Child (2006) Early Exposure to Toxic Substances Damages Brain Architecture. Working Paper No. 4. Center on the Developing Child at Harvard University, Cambridge.

[16] Julvez, J. and Grandjean, P. (2009) Neurodevelopmental Toxicity Risks Due to Occupational Exposure to Industrial Chemicals during Pregnancy. Industrial Health, 47, 459-468. https://doi.org/10.2486/indhealth.47.459

[17] Lawler, C.P., Croen, L.A., Grether, J.K. and Van de Water, J. (2004) Identifying En- 
vironmental Contributions to Autism: Provocative Clues and False Leads. Mental Retardation and Developmental Disabilities Research Reviews, 10, 292-302. https://doi.org/10.1002/mrdd.20043

[18] American Psychiatric Association (2000) Diagnostic and Statistical Manual of Mental Disorders, (DSM-5 $\left.{ }^{\oplus}\right) 2013$ Text Revision. 4th Edition, American Psychiatric Association, Washington DC.

[19] Froehlich, W. and Fung, L.K. (2012) Autism, Comorbidity in Psychiatry, Social Behavior, Pervasive Developmental Disorder, Addiction.

[20] CDC (Centers for Disease Control and Prevention) (2014) Prevalence of Autism Spectrum Disorders-Autism and Developmental Disabilities Monitoring Network, 14 Sites, United States, 2008. MMWR Surveillance Summaries, 61, 1-19.

[21] Lagunju, I.A., Bella-Awusah, T.T. and Omigbodun, O.O. (2014) Autistic Disorder in Nigeria: Profile and Challenges to Management. Epilepsy \& Behavior, 39C, 126-129. https://doi.org/10.1016/j.yebeh.2014.08.020

[22] Baxter, A.J., et al. (2015) The Epidemiology and Global Burden of Autism Spectrum Disorders. Psychological Medicine, 45, 601-613. https://doi.org/10.1017/S003329171400172X

[23] Modabbernia, A., Velthorst, E. and Reichenberg, A. (2017) Environmental Risk Factors for Autism: An Evidence-Based Review of Systematic Reviews and Meta-Analyses. Molecular Autism, 8, 13. https://doi.org/10.1186/s13229-017-0121-4

[24] Ronald, A. and Hoekstra, R.A. (2011) Autism Spectrum Disorders and Autistic Traits: A Decade of New Twin Studies. American Journal of Medical Genetics Part B: Neuropsychiatric Genetics, 156, 255-274. https://doi.org/10.1002/ajmg.b.31159

[25] Bouchard, M.F., Sauvé, S., Barbeau, B., Legrand, M., Brodeur, M.Ė., et al. (2011) Intellectual Impairment in School-Age Children Exposed to Manganese from Drinking Water. Environmental Health Perspectives, 119, 138-143. https://doi.org/10.1289/ehp.1002321

[26] Lanphear, B.P., Hornung, R., Khoury, J., Yolton, K., Baghurst, P., et al. (2005) Low-Level Environmental Lead Exposure and Children's Intellectual Function: An International Pooled Analysis. Environmental Health Perspectives, 113, 894-899. https://doi.org/10.1289/ehp.7688

[27] El Baz Mohamed, F., et al. (2015) Assessment of Hair Aluminum, Lead, and Mercury in a Sample of Autistic Egyptian Children: Environmental Risk Factors of Heavy Metals in Autism. Behavioural Neurology, 2015, Article ID: 545674. https://doi.org/10.1155/2015/545674

[28] Adams, J.B., Baral, M., Geis, E., et al. (2009) The Severity of Autism Is Associated with Toxic Metal Body Burden and Red Blood Cell Glutathione Levels. Journal of Toxicology, 2009, Article ID: 532640. https://doi.org/10.1155/2009/532640

[29] Geier, D.A., King, P.G., Sykes, L.K. and Geier, M.R. (2008) A Comprehensive Review of Mercury Provoked Autism. Indian Journal of Medical Research, 128, 383-411.

[30] Omotosho, I.O., Akinade, A.O. and Lagunju, I.A. (2018) Calcium and Magnesium Levels Are Down-Regulated in Nigeria Children with Autism Spectrum Disorder and Cerebral Palsy. Neuroscience and Medicine, 9, 159-170.

https://doi.org/10.4236/nm.2018.93016

[31] Lidsky, T.I. and Schneider, J.S. (2005) Autism and Autistic Symptoms Associated with Childhood Lead Poisoning. Journal of Applied Research in Clinical and Experimental Therapeutics, 5, 80-87. 
[32] Mason, L.H., Harp, J.P. and Han, D.Y. (2014) Pb Neurotoxicity: Neuropsychological Effects of Lead Toxicity. BioMed Research International, 2014, Article ID: 840547. https://doi.org/10.1155/2014/840547

[33] Brookes, P.S., Yoon, Y., Robotham, J.L., Anders, M.W. and Sheu, S.-S. (2004) Calcium, ATP, and ROS: A Mitochondrial Love-Hate Triangle. American Journal of Physiology, 287, C817-C833. https://doi.org/10.1152/ajpcell.00139.2004

[34] Mutter, J., Naumann, J., Schneider, R., Walach, H. and Haley, B. (2005) Mercury and Autism: Accelerating Evidence. Neuroendocrinology Letters, 26, 439-446.

[35] McNeill, J.H., Yuen, V.G., Hoveyda, H.R. and Orvig, C. (1992) Bis(maltolato)oxovanadium(IV) Is a Potent Insulin Mimic. Journal of Medicinal Chemistry, 35, 1489-1491. https://doi.org/10.1021/jm00086a020

[36] Rehder, D. (2013) Vanadium. Its Role for Humans. Metal Ions in Life Sciences, 13, 139-169. https://doi.org/10.1007/978-94-007-7500-8_5

[37] Madsen, E. and Gitlin, J.D. (2007) Copper and Iron Disorders of the Brain. Annual Review of Neuroscience, 30, 317-337. https://doi.org/10.1146/annurev.neuro.30.051606.094232

[38] Davis, J.M. and Svendsgaard, D.J. (1990) Nerve Conduction Velocity and Lead: A Critical Review and Meta-Analysis. In: Johnson, B.L., Ed., Advances in Neurobehavioural Toxicology, Lewis Publishers, Chelsea, 353-376.

[39] Mattie, M.D., McElwee, M.K. and Freedman, J.H. (2008) Mechanism of Copper-Activated Transcription: Activation of AP-1, and the JNK/SAPK and p38 Signal Transduction Pathways. Journal of Molecular Biology, 383, 1008-1018. https://doi.org/10.1016/j.jmb.2008.08.080

[40] Scott, R.J., Murrough, J.W., Han, M.-H., Charney, D.S. and Nestler, E.J. (2012) Neurobiology of Resilience Trace Elements after Dietary Exposure to Toxic Metals. Biological Trace Element Research, 23, 25-53.

[41] Russo, A.J. and Devito, R. (2011) Analysis of Copper and Zinc Plasma Concentration and the Efficacy of Zinc Therapy in Individuals with Asperger's Syndrome, Pervasive Developmental Disorder Not Otherwise Specified (PDD-NOS) and Autism. Biomark Insights, 6, 127-133. https://doi.org/10.4137/BMI.S7286

[42] Priya, L. and Geetha, A. (2011) Level of Trace Elements (Copper, Zinc, Magnesium and Selenium) and Toxic Elements (Lead and Mercury) in the Hair and Nail of Children with Autism. Biological Trace Element Research, 142, 148-158. https://doi.org/10.1007/s12011-010-8766-2

[43] Crăciun, E.C., Bjørklund, G., Tinkov, A.A., Urbina, M.A., Skalny, A.V., Rad, F. and Dronca, E. (2016) Evaluation of Whole Blood Zinc and Copper Levels in Children with Autism Spectrum Disorder. Metabolic Brain Disease, 31, 887-890. https://doi.org/10.1007/s11011-016-9823-0

[44] Laura, R.J., Deth, R.C. and Ralston, N.V.C. (2014) Potential Role of Selenoenzymes and Antioxidant Metabolism in Relation to Autism Etiology and Pathology. Autism Research and Treatment, 2014, Article ID: 164938. https://doi.org/10.1155/2014/164938

[45] James, S.J., Cutler, P., Melnyk, S., Jernigan, S., Janak, L., Gaylor, D.W. and Neubrander, J.A. (2004) Metabolic Biomarkers of Increased Oxidative Stress and Impaired Methylation Capacity in Children with Autism. The American Journal of Clinical Nutrition, 80, 1611-1617. https://doi.org/10.1093/ajcn/80.6.1611

[46] Blaurock-Busch, E., Amin, O.R., Dessoki, H.H. and Rabah, T. (2012) Toxic Metals and Essential Elements in Hair and Severity of Symptoms among Children with 
Autism. Maedica, 7, 38-48. https://doi.org/10.1016/S0924-9338(12)74444-9

[47] Priya, M.D. and Geetha, A. (2010) Level of Trace Elements (Copper, Zinc, Magnesium and Selenium) and Toxic Elements (Lead and Mercury) in the Hair and Nail of Children with Autism. Biological Trace Element Research, 142, 148-158.

[48] Jory, J. and Woody, R. (2008) Red-Cell Trace Minerals in Children with Autism McGinnis. American Journal of Biochemistry and Biotechnology, 4, 101-104. https://doi.org/10.3844/ajbbsp.2008.101.104 